Journal of Physical Science, Vol. 28(2), 161-179, 2017

\title{
Development of Solid-state Reference Electrode Based on Sodium Polyanethol Sulfonate Immobilised on Cellulose Acetate
}

\author{
Sagir Alva, ${ }^{1 *}$ Aiman Aziz, ${ }^{2}$ Mohd Ismahadi Syono ${ }^{3}$ and Darwin Sebayang ${ }^{1}$ \\ ${ }^{1}$ Mechanical Engineering Department, Faculty of Engineering, Universitas Mercu Buana, \\ Jl. Meruya Selatan No. 01, Kembangan, Jakarta-11650, Indonesia \\ ${ }^{2}$ Photonics R\&D, MIMOS Semiconductor (M) Sdn Bhd, Technology Park Malaysia, \\ 57000 Kuala Lumpur, Malaysia \\ ${ }^{3}$ Advanced Devices Lab, MIMOS Semiconductor (M) Sdn Bhd, Technology Park \\ Malaysia, 57000 Kuala Lumpur, Malaysia \\ *Corresponding author: sagir.alva@mercubuana.ac.id
}

Published online: 15 August 2017

To cite this article: Alva, S. et al. (2017). Development of solid-state reference electrode based on sodium polyanethol sulfonate immobilised on cellulose acetate. J. Phys. Sci., 28(2), 161-179, https://doi.org/10.21315/jps2017.28.2.11

To link to this article: https://doi.org/10.21315/jps2017.28.2.11

\begin{abstract}
In this study, we successfully developed a solid-state reference electrode based on sodium polyanethol sulfonate (SPS) immobilised on a cellulose acetate membrane and coated on a layer of polypyrrole on top of a carbon screen-printed electrode (SPE). We varied the concentration of SPS salt from $1 \%$ to $5 \%(w / v)$ and achieved an optimal concentration of 4\%. SPS optimisation test was performed by varying concentrations of $\mathrm{KCl}$ and $\mathrm{pH}$ buffer solution. The slope obtained for $4 \%$ SPS was $3.5 \pm 0.3$ with a residual standard deviation (RSD) of 9.3\% of $\mathrm{KCl}$ solution, whereas the slope obtained for $\mathrm{pH}$ buffer solution was $3.4 \pm 0.2$ with 1.2\% RSD. The stability test in pH 7 buffer and 10 $10^{-3}$ $M \mathrm{KCl}$ yielded drift at $<0.4 \mathrm{mV} / \mathrm{h}$ for $60 \mathrm{~h}$ of continuous monitoring. We also performed tests using standard $\mathrm{NH}_{4}+, \mathrm{K}+$ and $\mathrm{NO}_{3}$ - ion-selective electrode sensors, and the slopes measured were respectively $52.4 \pm 0.4,51.4 \pm 0.4$, and $-52.3 \pm 0.9 \mathrm{mV} /$ dec with a dynamic range of $0.1-10^{-5} \mathrm{M}$.
\end{abstract}

Keywords: Solid-state reference electrode, poly (anethol sulfonic acid), cellulose acetate, screen-printed electrode, sodium polyanethol

(C) Penerbit Universiti Sains Malaysia, 2017. This work is licensed under the terms of the Creative Commons Attribution (CC BY) (http://creativecommons.org/licenses/by/4.0/). 


\section{INTRODUCTION}

An analysis method based on potentiometric ion has been widely known since the 1970s. This method has been used in various types of ion measurement applications, such as medical, environmental, food, beverage industry, and many more. The measurement of potential value of the system is conducted on zero current condition. ${ }^{1,2}$ This method can measure very low ionic concentrations that is in $10^{-10} \mathrm{M}$ or in parts per trillion (ppt). ${ }^{3}$ According to International Union of Pure and Applied Chemistry (IUPAC), potentiometric analysis measures the potential difference that occurs between the working and reference electrodes, which is directly proportional to the logarithm of the concentration of ions. The working electrode is an electrode that has an ion-selective membrane against the target, which is commonly referred as ion-selective electrode (ISE). ${ }^{4}$ Potentiometric measurement will follow the Nernst equation:

$$
E M F=E^{o}+\frac{2.303 R T}{Z F} \log \left[a_{i}\right]
$$

where $E^{\circ}$ is an intercept whose value is tied to the state of the membrane and ion interference; $R, T$, and $F$ are a universal gas constant, temperature, and Faraday's constant respectively; $Z$ is the ionic charge of the analytes; and $a_{\mathrm{i}}$ concentration of analytes..$^{5-6}$

One critical component in potentiometric measurement technique is the reference electrode, which is as important as the working electrode. Till date, research on reference electrode has not been conducted as much as the research on the development of working electrode. Thus, there is an urgent need to conduct further research on reference electrodes. ${ }^{7,8}$

In potentiometric techniques, reference electrode is employed to determine the potential of working electrode. A major feature of reference electrode is the ability to maintain a steady potential over enormous range that should not be affected by sample size and its environment. ${ }^{9}$ Typical reference electrodes used are calomel and $\mathrm{Ag} / \mathrm{AgCl}$-based electrodes. Both of these are usually large, making them incompatible when coupled with micro-sized or planar working electrode. It is inseparable from the evolution of micro-sized working electrode rapidly. ${ }^{10-12}$

To reach the stated goal, research related to the maturation of the reference electrode is considered every bit of the potential areas to be built up. In recent years, several studies on small and planar reference electrodes have been recorded, such as research conducted by Kisiel et al. who utilised poly( $n$-butyl acrylate) 
membrane with lipophilic salts, such as potassium tetrakis ( $p$-chlorophenyl) borate (KTpClPB). ${ }^{13}$ Meanwhile, Renata et al. used a PVC polymer containing ionic liquid. ${ }^{14}$ The use of two different types of lipophilic salts of similar concentration has also been reported for the miniaturisation of reference electrode. Both lipophilic salts such as KTpClPB and tridodecylmethylammonium chloride (TDMA-Cl) can be immobilised on poly(urethane) (PU) membrane. ${ }^{15,16}$

Even so, problems frequently arise from planar reference electrode due to leaching of components over time. In addition, the formation of a layer of air trapped between the surface of the electrode and the membrane seriously affects the stability of reference electrode. ${ }^{17}$

To overcome this problem, in this work, the authors used ionic polymers such as sodium polyanethol sulfonate (SPS) salt as an electrolyte in a solid-state reference electrode. Ionic polymer-based membrane contains a large number of charges that can be ionised in water and other aprotic solvents. ${ }^{18}$ The chemical structure of polymers can be seen in Figure 1. Referring to Nernst equation, if the charge value of the chemicals $(z)$ is high then the potential value obtained will be low. Therefore, a large number of charge on the ionic polymers will induce the potential value of the planar electrode toward 0 , whereas if the charge exceeds 60 , then the predicted slope will be $<1 \mathrm{mV}$. This corresponds to the ideal characteristics of the reference electrode potential unperturbed by environmental changes. ${ }^{19}$

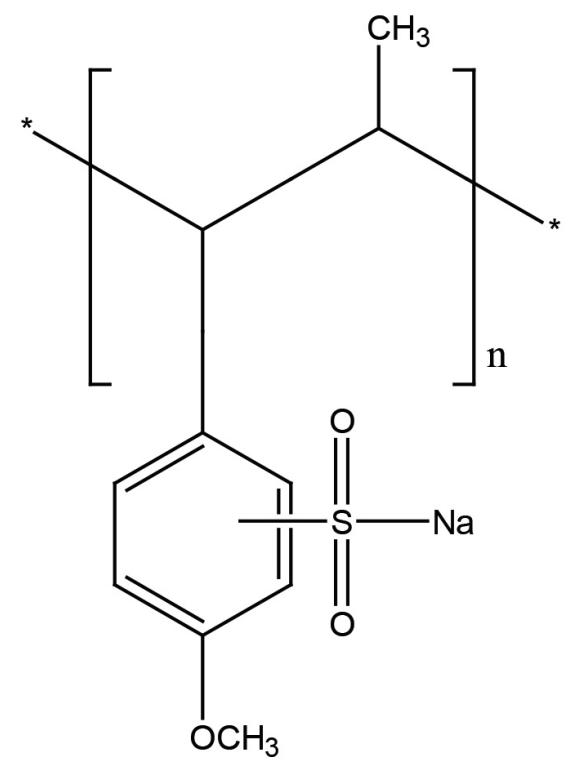

Figure 1: Chemical structure of SPS salt. 


\section{EXPERIMENTAL}

\subsection{Materials}

The ionic polymer of sodium polyanethol sulfonate $98 \%$ and cellulose acetate were obtained from Sigma Aldrich. Tetrahydrofuran (THF), potassium chloride $(\mathrm{KCl})$, nitric acid $\left(\mathrm{KNO}_{3}\right)$, ammonium chloride $\left(\mathrm{NH}_{4} \mathrm{Cl}\right)$, and monomer pyrrole 98\% were purchased from Merck, whereas the buffer solution with $\mathrm{pH} 4,7$ and 10 were purchased from Fisher Scientific. We purchased powder polisher $\mathrm{Al}_{2} \mathrm{O}_{3}$ from Metrohm.

\section{METHODS}

\subsection{Preparation of Electrode Transducers}

The carbon screen printed electrode (SPE) (Scrint Print BHD, Malaysia) was scrubbed with $\mathrm{Al}_{2} \mathrm{O}_{3}$ powder for approximately $30 \mathrm{~min}$ and then washed with deionised water until clear. Next, the electrodes were rinsed and sonicated for 1 min to get rid of $\mathrm{Al}_{2} \mathrm{O}_{3}$ dirt and particle remnants that sticked to the surface of the electrode. After sonication, the electrode was again rinsed and cleaned with deionised water and dried with a tissue paper. After drying, the carbon SPE was soaked in a solution containing monomers of $0.5 \mathrm{M}$ pyrrole and $1 \mathrm{M} \mathrm{KCl}$ as a dopant and connected to Autolab PGSTAT 128N MODEL potentiostat for electropolymerisation process. Carbon SPE acted as a working electrode, Pt electrode as counter electrode, and $\mathrm{Ag} / \mathrm{AgCl}$ double junction electrode as a reference electrode. The process of polymerisation was started by supplying a current density of $2 \mathrm{~mA} / \mathrm{cm}^{2}$ for $90 \mathrm{sec}$. The completion of polypyrrole polymerisation process was marked by a dark purple layer formed on the surface of carbon SPE. After that, the carbon SPE was rinsed with deionised water and was dried using a tissue paper.

\subsubsection{Preparation and characterisation of solid-state reference electrode}

SPE coated with a layer of polypyrrole was deposited with a $50 \mu \mathrm{L}$ cocktail of polymeric ions containing $5 \%$ cellulose acetate at varying concentrations $(1 \%-$ $5 \%, \mathrm{w} / \mathrm{v}$ ) of ionic SPS polymer and THF as a solvent. After the surface of the electrode was coated with the cocktail, the electrode was left to dry overnight at room temperature. The completed reference electrode was further tested for the Nernstian number at various concentrations and for $\mathrm{pH}$ using $\mathrm{KCl}$ solution wherein the solid-state reference electrode acted as a working electrode. In addition, a stability test under continuous monitoring in $\mathrm{KCl} 10^{-3} \mathrm{M}$ and $\mathrm{pH} 7$ buffer solution 
was performed. In the final test, the response to $\mathrm{NH}_{4}{ }^{+}, \mathrm{K}^{+}$and $\mathrm{NO}_{3}{ }^{-}$ISE electrode was measured, where the measurement outcomes were compared to ISE paired with a standard double junction reference electrode. All the tests were conducted using ion meter Orion 5 Star.

\section{RESULTS AND DISCUSSION}

\subsection{Characterisation of Electrode Transducers}

Prior to testing the performance of the solid-state reference electrode, some headway toward the characterisation of a carbon SPE after coating polypyrrolechloride $(\mathrm{PPy} / \mathrm{Cl})$, and also after placing the cellulose acetate membrane/SPS need to be attained. This aims to ensure that polypyrrole was polymerised and SPS salt is present in the system of the solid-state reference electrode. The characterisation was performed by visual inspection, scanning electron microscopy (SEM), cyclic voltammetry $(\mathrm{CV}), 0.1 \mathrm{M} \mathrm{KCl}$ solution, and potentiometric measurements.

With the aid of visual inspection and SEM analysis, differences were noticed between the bare carbon electrode, after coating with $\mathrm{PPy} / \mathrm{Cl}$, and after deposition of cellulose acetate membrane/SPS on top of PPy/Cl layer (Figure 2). In Figure 2(a), an electrode with scratches, black layer, and SEM image shows un-homogeneous thin layer spots. Furthermore, after polymerisation, pyrrole monomers converted to polypyrrole on the surface of the carbon electrode forming a new layer. As seen in Figure 2(b), the surface of the electrode becomes thicker and smoother. This is supported by a SEM image showing real change, whereby after polymerisation, a layer with smoother texture and shape like a stack of raisins was formed. This picture is in accordance with the data presented in the previous research. ${ }^{20,21}$ Figure 2(c) shows the presence of a shiny layer that is transparent and slippery like plastic, which is a layer of cellulose acetate membrane that contains SPS salt. SEM was conducted using cross section of the side edges, where the thickness of the layers was visible that the membrane is less about $436 \mathrm{~mm}$. 


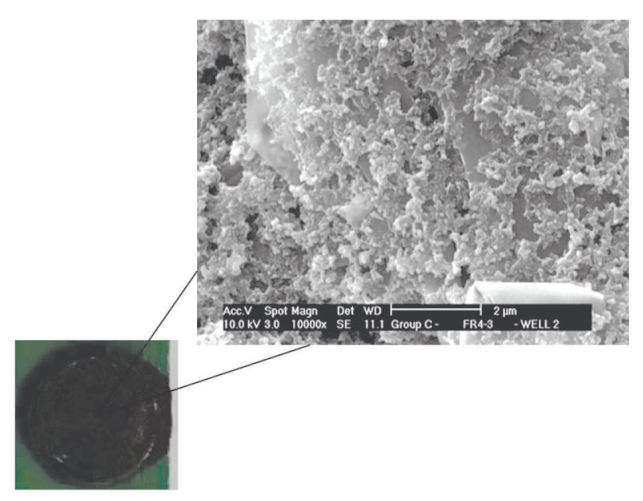

(a)

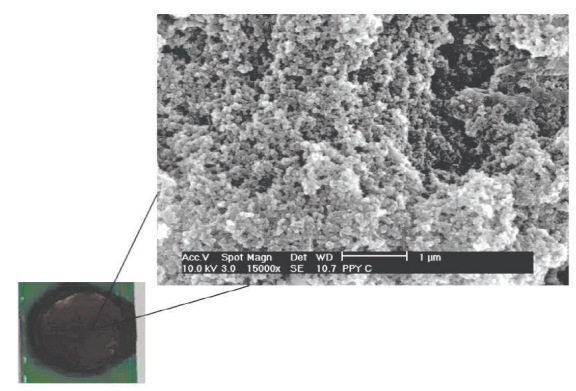

(b)

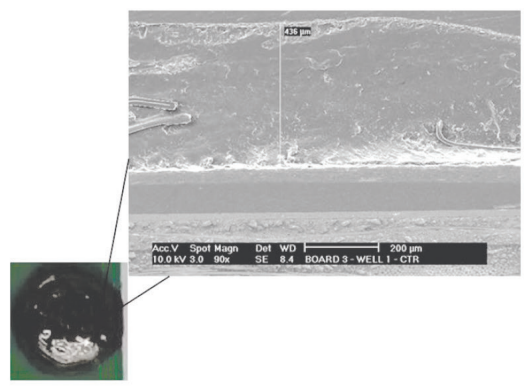

(c)

Figure 2: Visual and scanning electron microscopy (SEM) of electrode (a) carbon electrode, (b) after polymerisation of PPy, and (c) after deposition of cellulose acetate containing SPS salt. 
Figure 3 and Table 1 show the presence of the $\mathrm{PPy} / \mathrm{Cl}$ layer and cellulose acetate/ SPS membranes. Figure 3 also shows the CV graph, a carbon electrode, and PPy/ $\mathrm{Cl}$ layer that were performed with the use of three cells in a solution of $0.1 \mathrm{M}$ $\mathrm{KCl}$, where carbon electrodes and $\mathrm{PPy} / \mathrm{Cl}$ also acted as the working electrode. The reference electrode was a double junction of standard $\mathrm{Ag} / \mathrm{AgCl}$ electrode and the counter electrode was a Pt electrode. Figure 3(a) shows the CV image of the carbon electrode and this form is the specific pattern of the carbon electrode. As seen in Figure 3(a), carbon electrodes were not showing oxidation peak at $-1 \mathrm{~V}$ to $1 \mathrm{~V}$ window, where the scan rate used was $100 \mathrm{mV} / \mathrm{s}$, whereas we also found that the carbon electrode's CV was very thin. This suggests that there is a surface on the carbon electrode that is not contaminated from other materials. ${ }^{22,23}$ Figure 3(b) shows the $\mathrm{CV}$ of $\mathrm{PPy} / \mathrm{Cl}$ in a solution of $0.1 \mathrm{M} \mathrm{KCl}$, wherein the window between $-1 \mathrm{~V}$ and $0.4 \mathrm{~V}$ was seen as the peak oxidation on region $0 \mathrm{~V}$ and the peak reduction at $-0.8 \mathrm{~V}$. This indicates that $\mathrm{PPy} / \mathrm{Cl}$ had formed above the surface layer of carbon electrodes. In addition, the presence of peaks of oxidation and reduction also indicates that the $\mathrm{PPy} / \mathrm{Cl}$ formed will make electrode transducer having the ability to make charge transfer on the surface layer of carbon. ${ }^{24}$

To ascertain the presence of a $\mathrm{PPy} / \mathrm{Cl}$ layer and also the presence of SPS salt on the cellulose acetate membrane, we tested the cellulose acetate membranes using the Nernstian number measurement in solution buffer at $\mathrm{pH} \mathrm{4,7}$ and 10. This was performed because $\mathrm{PPy} / \mathrm{Cl}$ is highly prone to deprotonation, making it very sensitive to $\mathrm{pH}$ changes, which will lead to the occurrence of positive slope close to the Nernstian number. ${ }^{25}$ Meanwhile, the presence of SPS salt on the cellulose membrane and on the surface of $\mathrm{PPy} / \mathrm{Cl}$ will cause the response slope to be dropped significantly (Table 1). It is inseparable from the SPS salt, which is a type of polyion that has a large charge, thus causing potential changes on the surface of the electrodes. The presence of $\mathrm{H}^{+}$on the surface of the transducer is not enough to affect the change in the potential at the surface of the transducer. ${ }^{26}$ Different things are indicated if the cellulose acetate membranes used do not contain a salt of SPS (Table 1). This does not change the response of the electrode transducer. Transducer still retains the characteristics of the response of $\mathrm{PPy} / \mathrm{Cl}$, which is sensitive to alterations in $\mathrm{pH}$. This is because the properties of cellulose acetate membrane, that is porosity with no charge, ${ }^{27,28}$ caused the samples to enter freely into the membrane toward the surface of the electrode without being influenced by changes of the charge on the membrane. 


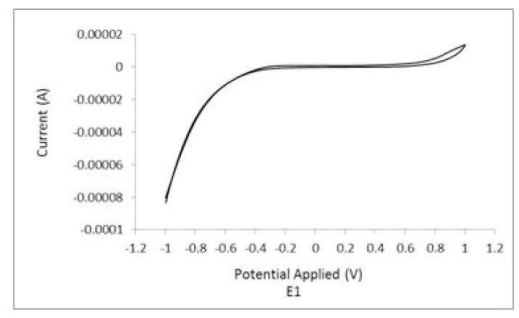

(a)

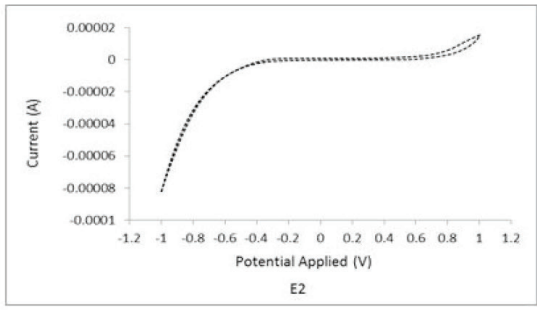

(b)

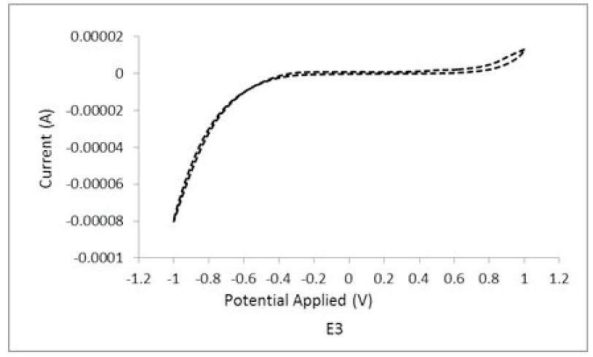

(c)

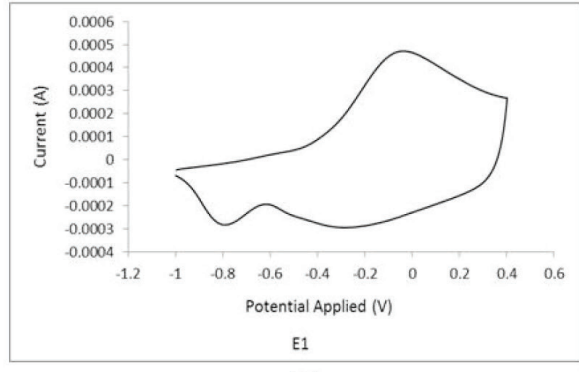

(d)

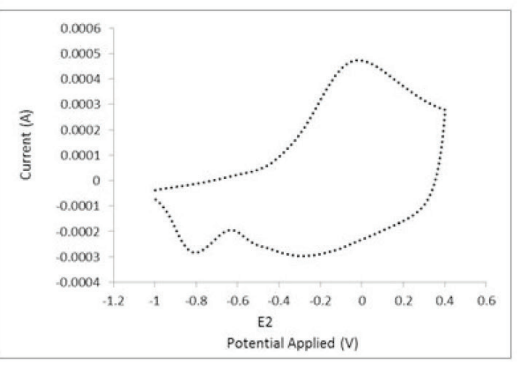

(e)

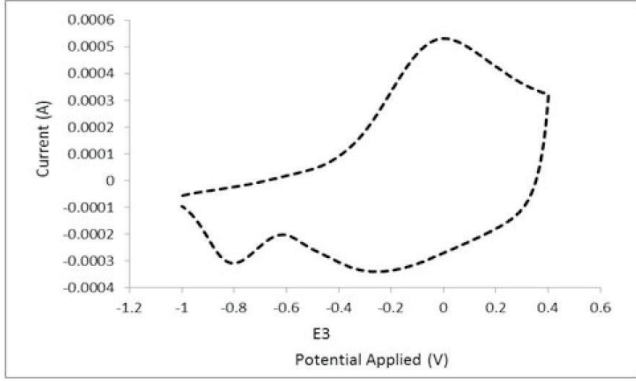

(f)

Figure 3: The cyclic voltammetry of $(\mathrm{a}-\mathrm{c})$ carbon electrode $(\mathrm{d}-\mathrm{f})$ after PPy deposited. Testing in $0.1 \mathrm{M} \mathrm{KCl}$ solution. 
Table 1: Slope comparison of $\mathrm{PPy} / \mathrm{Cl}$ layer and after cellulose acetate/SPS deposited on top of $\mathrm{PPy} / \mathrm{Cl}$ layer.

\begin{tabular}{lccc}
\hline Parameters & PPy/Cl & Cellulose acetate bare & $\begin{array}{c}\text { Cellulose acetate/SPS (top of PPy/ } \\
\text { Cl layer) }\end{array}$ \\
\hline Slope (mV/dec) & 55 & 54.7 & 3.4 \\
SD & 2.2 & 1.9 & 0.2 \\
RSD (\%) & 4.0 & 4.4 & 1.2 \\
$r^{2}$ & 0.9991 & 0.9986 & 0.9884 \\
\hline
\end{tabular}

Note: PPyCl:polypyrrole-chloride RSD: relative standard deviation; SD: standard deviation; SPS: sodium polyanethol sulfonate.

\subsection{Effects of Sodium Salt of Poly(Anethol Sulfonic Acid)}

The sodium salt of poly(anethol sulfonic acid) is a type of polymeric ion, which is also known as SPS. It is usually used as an anticoagulant in blood samples of the bacteria breeding in a bottle. In addition, SPS also serves as a barrier to reproductive cells that can intervene with the growth of bacteria in a sample of media. ${ }^{29}$ Moreover, SPS is also employed as an ionophore in the preparation of sodium ISE. ${ }^{30}$

In this work, SPS at varying concentrations was immobilised on cellulose acetate membrane and applied on a solid-state reference electrode matrix. The choice of the cellulose acetate membrane was based on its properties such as easy decomposability, thermoplastic in nature, easily soluble in various organic solvents, flexibility, and possesses good mechanical durability. In addition to these, cellulose acetate membrane has a porous physical structure, which helps in the movement of both ions and water molecules toward the sample or in the opposite direction. ${ }^{31-34}$

As seen in Table 2, the concentration of SPS salt immobilised onto the cellulose acetate membrane gives an impression of the response slope when tested at various concentrations of $\mathrm{KCl}$ solution and $\mathrm{pH}$ of the solution when the solid-state reference electrode was coupled with the standard $\mathrm{Ag} / \mathrm{AgCl}$ reference electrode with double junction type. In this work, the solid-state reference electrode functioned as a working electrode. 
Table 2: Slope of various types of solid state reference electrode in the various concentrations of a $\mathrm{KCl}$ solution and $\mathrm{pH}$ of buffer solution.

\begin{tabular}{ccccccc}
\hline \multirow{2}{*}{$\begin{array}{l}\text { SPS } \\
\text { concentration } \\
(\% \mathrm{w} / \mathrm{v})\end{array}$} & \multicolumn{3}{c}{ KCl solution } & \multicolumn{3}{c}{ Buffer solutions } \\
\cline { 2 - 7 }$(\mathrm{mV} / \mathrm{dec})$ & RSD (\%) & $\mathrm{r}^{2}$ & $\begin{array}{c}\text { Slope } \\
(\mathrm{mV} / \mathrm{dec})\end{array}$ & $\mathrm{RSD}(\%)$ & $\mathrm{r}^{2}$ \\
\hline 1 & $7.6 \pm 0.4$ & 5.1 & 0.9847 & $7.9 \pm 0.4$ & 4.8 & 0.9954 \\
2 & $5.6 \pm 0.5$ & 8.2 & 0.9900 & $5.5 \pm 0.2$ & 3.9 & 0.9866 \\
3 & $4.6 \pm 0.1$ & 2.7 & 0.9935 & $4.7 \pm 0.2$ & 4.5 & 0.9965 \\
4 & $3.5 \pm 0.3$ & 9.3 & 0.9946 & $3.4 \pm 0.2$ & 1.2 & 0.9884 \\
5 & $3.5 \pm 0.2$ & 4.8 & 0.9920 & $3.8 \pm 0.2$ & 4.1 & 0.9930 \\
\hline
\end{tabular}

Note: RSD: relative standard deviation; SPS: sodium polyanethol sulfonate.

In this study, we have seen that the concentration of SPS salt will influence the value of the slope of the solid-state reference electrodes. This phenomenon is seen because of the amount of the charge contained in the polymeric ionic salts such as SPS. This great amount of charge if inserted into Equation 1 will make the Nernstian number or the slope to go down. ${ }^{19}$

In the manufacture of ionic sensors, lipophilic salts are added to increase the dynamic side of the membrane, allowing ions to move toward the layer to of the membrane. ${ }^{35-37}$ With a similar concept, the addition of SPS salts should also work as lipophilic salts in the solid-state reference electrode prepared in this work. If this is determined, the slope resulting from the measurements tends to sustain a positive response, which may be inseparable from the negative charge of the functional groups of sulfonate. Then, the lining of the membrane will tend to deliver a large negative active site thereby making the positively charged ions such as $\mathrm{K}^{+}$and $\mathrm{H}^{+}$ to extract into the membrane and provide stimulus potential value (Figure 4). ${ }^{38,39}$

Studies on the variations of the concentration of SPS aim to determine the optimal composition of the ingredients in the making of solid-state reference electrodes. Table 2 shows that with increasing concentration of SPS salt, the average Nernstian number will go down from 7.5 to 3.5 for $\mathrm{KCl}$ solution and 7.9 changes to 2.1 for $\mathrm{pH}$ buffer solution $(1 \%-4 \% \mathrm{w} / \mathrm{v})$. This is due to the increase in the concentration of SPS salt used that will also cause a rise in total charge of the lining membrane of the surface electrodes contained in the solid-state reference electrode. This will have a reduction in the Nernstian number. ${ }^{19}$ In addition, it will also increase the negative side of the cellulose acetate membrane. This will also improve competition between ions that are present in the sample to allow movement into the membrane of solid-state reference electrode so that the resulting slope also decreased. ${ }^{40}$ 


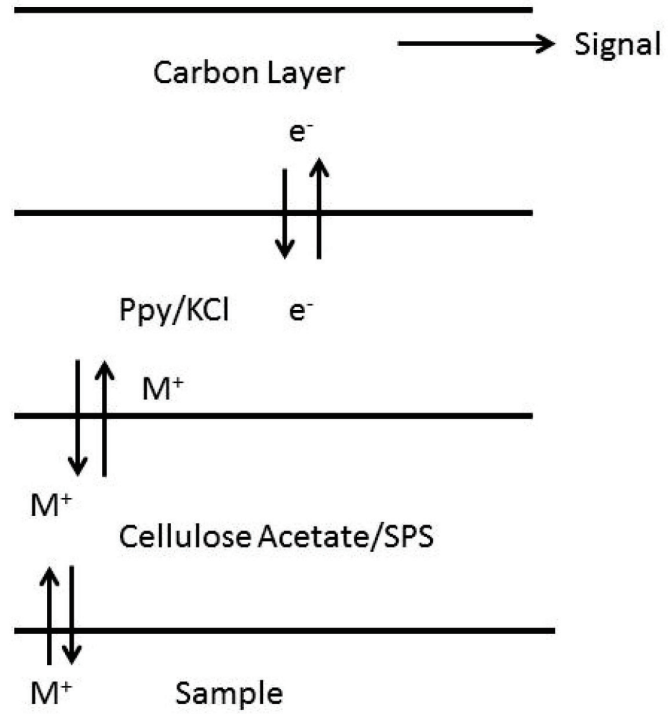

Figure 4: The mechanism of charge transfer process in a solid reference electrode.

Meanwhile, at a concentration of $4 \%-5 \%$, the number of Nernstian produced visible already a constant. This is because the total amount of charge on the film's layer of cellulose acetate membrane was already saturated. This will result in a charge balance in the solid-state reference electrode as it approaches the balancing stage. In a state of saturation, the resulting potential difference tends to be incessant. In summation, the equilibrium will also change direction, that is, from the membrane towards the sample. It appears at a $\mathrm{pH}$ testing solution, which slope at a concentration of $5 \%$ is somewhat higher than the concentration of $4 \% .{ }^{41,42}$

\subsection{Drift Study}

The reference electrode drift study was evaluated through the stability of the potential value. ${ }^{43}$ Stability was defined as the ability of the reference electrode to maintain at a constant potential within a certain time period. ${ }^{44}$ The reference electrodes were immersed in two types of solutions: $10^{-3} \mathrm{M}$ potassium chloride $(\mathrm{KCl})$ solution and buffer solution with $\mathrm{pH} 7$ for a continuous measurement of $60 \mathrm{~h}$. Figure 5 shows potential response measurement of reference electrodes versus time. Initially in the first $35 \mathrm{~h}$ of measurement period, there was a change in the potential value observed with a drift rate of $0.13 \mathrm{mV} / \mathrm{h}$ in $\mathrm{KCl}$ solution and $0.09 \mathrm{mV} / \mathrm{h}$ in the $\mathrm{pH} 7$ buffer solution. Meanwhile, during the last $25 \mathrm{~min}$, reference electrodes that were immersed in $10^{-3} \mathrm{M} \mathrm{KCl}$ solution showed fairly significant drift of $0.33 \mathrm{mV} / \mathrm{h}$ or $73.7 \%$ drift increment. However, electrodes studied in buffer 
solution $\mathrm{pH} 7$ exhibits $0.26 \mathrm{mV} / \mathrm{h}$ drift rate or $188.9 \%$ drift increment. A good reference electrode drift rate is reported not exceeding $1 \mathrm{mV} / \mathrm{h} .{ }^{11-14,45-47}$

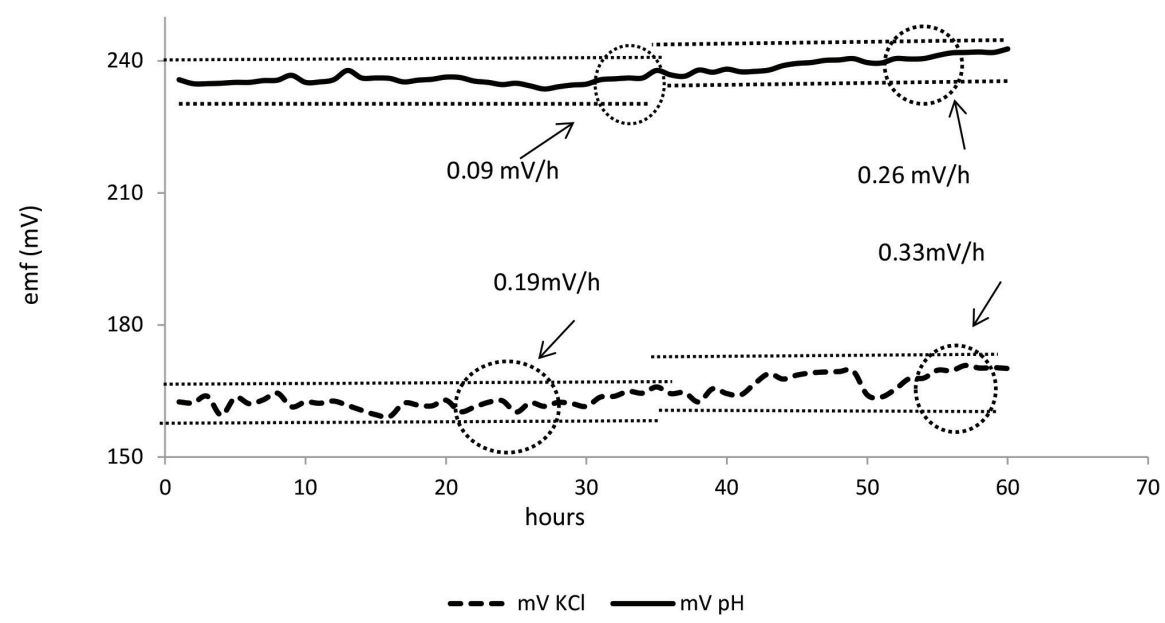

Figure 5: The stability of solid-state reference electrode potential value for $60 \mathrm{~h}$ in a solution of $10^{-3} \mathrm{M}$ of $\mathrm{KCl}$ and buffer solution at $\mathrm{pH} 7$.

The non-ideal effects existed in many sensors. The sensor drift can be influenced by many factors such as poor component entrapment in the polymer matrix. However, in this work, the drift was induced by the occurrence of leaching-off of SPS salt components from the polymer matrix of the cellulose acetate membrane. This leaching process was due to the apparent motion of ions from the membrane towards the sample or otherwise, as well as process water ingress into the cellulose acetate membrane. ${ }^{15,16,47}$ The porous form of cellulose acetate membrane also contributed to the onset of the process of leaching of SPS salts from the cellulose acetate matrix. ${ }^{29-34}$ From Figure 5, it can be observed that the stability of the solidstate reference electrode was initially low and started to degrade after $35 \mathrm{~h}$.

\subsection{Response vs. ISE}

To demonstrate the merit of the functional reference electrode, the developed SPS-based solid-state electrodes were evaluated by measuring its potential shift in comparison to commercial ISE sensors such as $\mathrm{NH}_{4}{ }^{+}, \mathrm{K}^{+}$and $\mathrm{NO}_{3}{ }^{-}$. A validation test of the selected ISE's versus standard $\mathrm{Ag} / \mathrm{AgCl}$ double junction reference electrode was also conducted with regard to Nerstian response.

Based on the result shown in Figure 6, it was observed that the commercial $\mathrm{NH}_{4}^{+}$, $\mathrm{K}^{+}$and $\mathrm{NO}_{3}^{-}$ISE sensors paired with solid-state reference electrode exhibited 
linear logarithmic relationship that agree to Nerst response. $\mathrm{NH}_{4}^{+}$and $\mathrm{K}^{+}$ISE sensors showed a positive slope response to positively charged ions, whereas $\mathrm{NO}_{3}{ }^{-}$ ion yields a negative slope response to negatively charged ions. ${ }^{51}$

This suggests that the solid-state reference electrode has a potential value that is almost unchanged despite changes in the concentration of samples and environment. This is an important feature of a solid-state reference electrode. ${ }^{9}$ This data is also supported by the value of the Nernstian number as displayed in Table 2 which shows the value that approximates the value of the Nernstian number, where the ideal number of values at a temperature of $25^{\circ} \mathrm{C}$ Nernstian is $59.16 \mathrm{mV} / \mathrm{dec}$. for monovalent ions. ${ }^{48}$

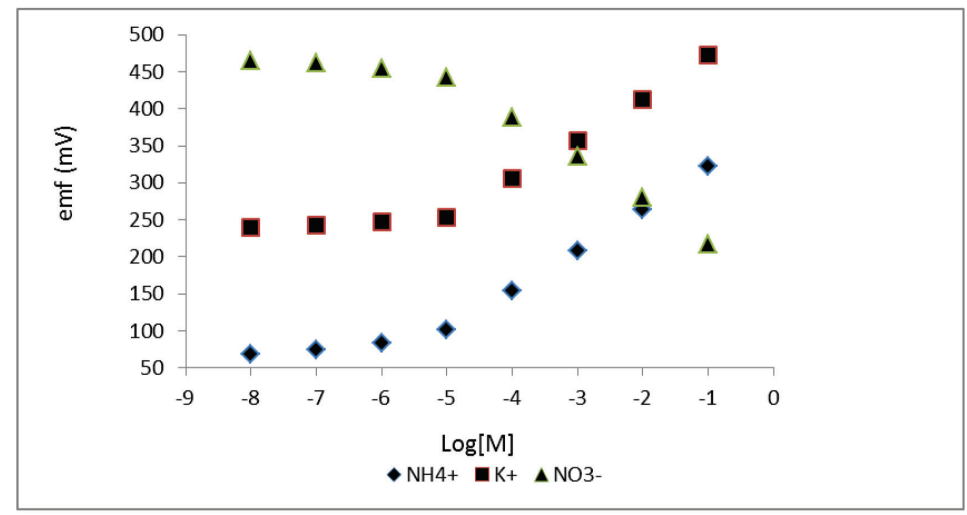

(a)

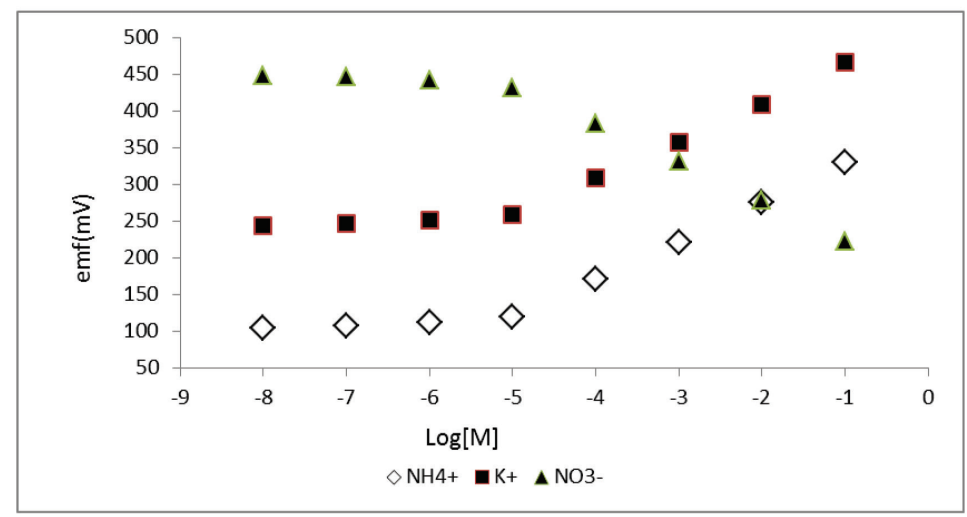

(b)

Figure 6: Response of commercial ion-selective electrode (ISE) sensors vs. (a) solidstate reference electrode, (b) commercial $\mathrm{Ag} / \mathrm{AgCl}$ double junction reference electrode. 
Based on the results tabulated in Table 3, comparable results were obtained for the SPS-based solid-state reference electrode's performance with the standard $\mathrm{Ag} / \mathrm{AgCl}$ double junction reference electrodes used. The Nerstian slope response generated by SPS solid-state reference was relatively low as compared to the standard $\mathrm{Ag} / \mathrm{AgCl}$ reference electrode. This is governed by the type of electrolyte used. ${ }^{11}$ The standard $\mathrm{Ag} / \mathrm{AgCl}$ reference electrodes are constructed with a liquidtype electrolyte inner filling solution. However, solid-type electrolyte was embedded on a solid-state reference electrode design. The solid-type electrolyte will affect the movement of ions, where the motion of the ions will be slightly stunted compared to the liquid-type electrolyte. This will cause a large increase in the value of the underground electrode which will decline the Nernstian number. ${ }^{52}$

Table 3: Comparability of the performance of ISE sensors paired with solid-state reference electrode and standard of $\mathrm{Ag} / \mathrm{AgCl}$ reference electrode with double junction type.

\begin{tabular}{|c|c|c|c|c|c|c|c|c|}
\hline \multirow[b]{2}{*}{ ISE } & \multicolumn{4}{|c|}{$\begin{array}{l}\text { vs. } \mathrm{Ag} / \mathrm{AgCl} \text { double junction reference } \\
\text { electrode standard }\end{array}$} & \multicolumn{4}{|c|}{ vs. solid-state reference electrode } \\
\hline & $\begin{array}{l}\text { Slope } \\
(\mathrm{mV} / \\
\mathrm{dec})\end{array}$ & LR (M) & $\begin{array}{l}\text { LOD } \\
\left(\times 10^{-6}\right. \\
\mathrm{M})\end{array}$ & $\mathrm{R}^{2}$ & $\begin{array}{l}\text { Slope } \\
(\mathrm{mV} / \mathrm{dec})\end{array}$ & $\mathrm{LR}(\mathrm{M})$ & $\begin{array}{l}\text { LOD } \\
\left(\times 10^{-6}\right. \\
\mathrm{M})\end{array}$ & $\mathrm{R}^{2}$ \\
\hline $\mathrm{NH}_{4}^{+}$ & $\begin{array}{l}55.5 \pm \\
1.0\end{array}$ & $0.1-10^{-5}$ & $\begin{array}{l}2.7 \pm \\
0.6\end{array}$ & 0.9992 & $\begin{array}{l}52.4 \pm \\
0.4\end{array}$ & $0.1-10^{-5}$ & $4.9 \pm 0.3$ & 0.9994 \\
\hline $\mathrm{K}^{+}$ & $\begin{array}{l}54.5 \pm \\
0.5\end{array}$ & $0.1-10^{-5}$ & $\begin{array}{l}4.9 \pm \\
0.5\end{array}$ & 0.9988 & $\begin{array}{l}51.4 \pm \\
0.4\end{array}$ & $0.1-10^{-5}$ & $4.7 \pm 0.2$ & 0.9990 \\
\hline $\mathrm{NO}_{3}^{-}$ & $\begin{array}{l}-55.9 \pm \\
0.5\end{array}$ & $0.1-10^{-5}$ & $\begin{array}{l}4.0 \pm \\
0.2\end{array}$ & 0.9990 & $\begin{array}{l}-52.3 \pm \\
0.9\end{array}$ & $0.1-10^{-5}$ & $4.9 \pm 0.5$ & 0.9989 \\
\hline
\end{tabular}

Note: LR: linear range ; LOD: limit of detection ; ISE: ion-selective electrode RSD: relative standard deviation; SPS: sodium polyanethol sulfonate.

In the membranous layers of solid-type electrolytes, such as ours, the movement of the ions occurs through the mechanism of ion jumps or hopping. ${ }^{53}$ In this mechanism, the lipophilic salts, such as salt of SPS, will form pools that are spread evenly throughout the membrane solids such as sprinkles of raisins in the bread. Ions will move by jumping from one pond to another nearby pond until it reaches the surface of the transducer polypyrrole found on top of a layer of carbon on the surface of the SPE electrode.

The other factor that causes low solid-state reference electrode's numerical Nernstian slope is the different size of electrode's design. The miniaturised designed planar solid-state reference electrode has a small area compared to the bulky commercial standard reference electrodes. The small design of the electrode will affect the capacity of electrolytes contained in the reference electrode, which 
contributes to a low Nerstian slope value. Consequently, it constrains the ability of electrolyte to pull ions into the membrane that later affects low sensor signal performance. The same behaviour of reference electrode has also been reported by Simonis et al. in 2004. ${ }^{12}$

\section{CONCLUSION}

In this work, a new solid-state reference electrode based on polymeric sodium salt of SPS ion has been successfully developed in a planar type formed. The solid-state electrode has been prepared via electropolymerisation of $\mathrm{PPy} / \mathrm{Cl}$ and drop-casted SPS membrane film assembly. The fabricated electrode has shown comparable linear logarithmic response similar to the standard $\mathrm{Ag} / \mathrm{AgCl}$ double junction electrode. Thus, the SPS-based solid-state reference electrode has demonstrated good stability with the achieved drift rate $<0.4 \mathrm{mV} / \mathrm{h}$ within $60 \mathrm{~h}$. Moreover, the developed solid-state reference electrode can be applied as an alternative reference electrode in the analysis using ISE method. In conclusion, the planar-type SPSbased solid-state reference electrode offers a free liquid maintenance, ease of handling, and high potential to be integrated into ion sensors array.

\section{ACKNOWLEDGEMENTS}

The authors gratefully thank MIMOS Berhad for supporting this work by providing laboratory facilities during this research. In addition, the authors wish to thank Universitas Mercu Buana especially the Mechanical Engineering Department for providing support during this study.

\section{REFERENCES}

1. Bakker, E. \& Pretsch, E. (2007). Modern potentiometry. Angewandte Chemie., 46, 5660-5668.

2. Bakker, E. (2004). Electrochemical sensors. Anal. Chem., 76, 3285-3298.

3. Lindner, E. \& Pendley, B. D. (2013). A tutorial on the application of ionselective electrode potentiometry: An analytical method with unique qualities, unexplored opportunities and potential pitfalls. Anal. Chim. Acta, $762,1-13$.

4. IUPAC. (1994). Recomendations for nomenclature of ion selectives electrodes. Pure \& Appl. Chem., 66, 2527-2536. 
5. Bakker, E. \& Pretsch, E. (2005). Potentiometric sensors for trace-level analysis. Trends Anal. Chem., 24, 199-207.

6. Wojciechowski, K. (2011). Hydration energy or hydration force? origin of ion-specificity in ion selective electrodes. Curr. Opin. Coll. Inter. Sci., 16, 601-606.

7. Suzuki, H. et al (1998). Problems associated with the thin-film ag/agcl reference electrode and a novel structure with improved durability. Sens. Actuat. B Chem., 46, 104-113.

8. Suzuki, H., Hiratsuka, T., Sasaki, S. \& Isao, K. (1998). Micromachined liquid-junction ag/agcl reference electrode. Sens. Actuat. B Chem., 46, 146154.

9. East, G. A. \& del Valle, M. A. (2000). Easy-to-make ag/agcl reference electrode. J. Chem. Ed., 77, 97.

10. Ge, S. et al. (2012). A disposable paper-based electrochemical sensor with an addressable electrode array for cancer screening. Chem. Comm., 48, 9397-9399.

11. Hassel, A. W., Fushimi, K. \& Seo, M. (1999). An agar-based silver/silver chloride reference electrode for use in micro-electrochemistry. Electrochem. Comm., 1, 180-183.

12. Simonis, A. et al. (2004). New concepts of miniaturised reference electrodes in silicon technology for potentiometric sensor systems. Sens. Actuat. B Chem., 103, 429-435.

13. Kiesel, A., Michalska, A. \& Maksymiuk, K. (2008). Plastic reference electrodes and plastic potentiometric cells with dispersion cast poly $(3,4-$ ethylenedioxythiophene) and poly(vinyl chloride) based membranes, Bioelectrochem., 71, 75-80.

14. Maminska, R., Dybko, A. \& Wroblewski, W. (2006). All-solid-state miniaturised planar reference electrodes based on ionic liquids. Sens. Actuat. B Chem., 115 552-557.

15. Lee, H. J. et al. (1998). Solvent-processible polymer membrane-based liquid junction-free reference electrode. Anal. Chem., 70, 3377-3383.

16. Yoon, H. J. et al. (2000). Solid-state ion sensors with a liquid junction-free polymer membrane-based reference electrode for blood analysis. Sens. Actuat. B Chem., 64, 8-14.

17. Rius-Ruiz, F. X. et al. (2011). Disposable planar reference electrode based on carbon nanotubes and polyacrylate membrane. Anal. Chem., 83, 5783-5788.

18. Lipar, I. et al. (2007). Thermodynamic characterization of polyanetholesulfonic acid and its alkaline salts. J. Phys. Chem., 111, 1013010136.

19. Mi, Y., Mathison, S. \& Bakker, E. (1999). Polyion sensors as liquid junctionfree reference electrodes. Electrochem. Solid-State Lett., 2, 198-200. 
20. Alva, S. et al. (2016). Synthesis and characterization of toluene sulfonic acid (tsa) doped polypyrrole nanoparticles: Effect of dopant concentrations. Int. J. Inno. Mech. Eng. Adv. Mater., 2, 1-9.

21. Utami, R. S. et al. (2016) effect of process parameters on the synthesis of polypyrrole by the taguchi method. M. J. Anal. Sci., 20, 660-669.

22. Reda, A. H. \& Gebremeskel, F. G. (2016). Determination of ascorbic acid in citrus sinensis and ananas comosus using poly (3, 4-ethylenedioxythiophene) modified glassy carbon electrode. Am. J. Appl. Chem., 4, 1-7.

23. Filipe, O. M. S. \& Brett, C. M. A. (2004). Characterization of carbon film electrodes for electroanalysis by electrochemical impedance. Electroanal., 16, 994-1001.

24. Quan, D. P. et al. (2001). A conductive polypyrrole based ammonium ion selective electrode. Environ. Monitor. Assess., 70, 153-165.

25. Alumaa, A. et al. (2004). Potentiometric properties of polypyrrole bilayers. Electrochim. Acta, 49, 1767-1774.

26. Bakker, E. \& Meyerhoff, M. E. (2000). Ionophore-based membrane electrodes: New analytical concepts and non-classical response mechanisms. Anal. Chim. Acta, 416, 121-137.

27. Ferrarezi, M. M. F. et al. (2013). Investigation of cllulose acetate viscoelastic properties in different solvents and microstructure. Euro. Poly. J., 49, 2730 2737.

28. Valente, A. J. M. et al. (2005). Permeation of water as a tool for characterizing the effect of solvent, film thickness and water solubility in cellulose acetate membranes. Euro. Poly. J., 41, 275-281.

29. Palarasah, Y. et al. (2010). Sodium polyanethole sulfonate as an inhibitor of activation of complement function in blood culture systems. J. Clin. Microb., 48, 908-914.

30. Ghalami-Choobar, B. \& Shafaghat-Lonbar, M. (2014). Thermodynamic investigation of the ternary mixed electrolyte $\left(\mathrm{NaCl}+\mathrm{Na}_{2} \mathrm{HCit}+\mathrm{H}_{2} \mathrm{O}\right)$ system using potentiometric measurements at $\mathrm{T}=(298.2$ and 308.2) K. $J$. Chem. Thermo., 78, 69-78.

31. Han, S. O. et al. (2008). Electrospinning of cellulose acetate nanofibers using a mixed solvent of acetic acid/water: Effects of solvent composition on the fiber diameter. Mater. Lett., 62, 759-762.

32. Nabi, S. A. \& Naushad, M. (2008). Synthesis, characterization and analytical applications of a new composite cation exchanger cellulose acetate-zr(IV) molybdophosphate. Coll. Surf. A Phys. Eng. Asp., 316, 217-225.

33. Tsioptsas, C. et al. (2010). Preparation and characterization of cellulose acetate- $\mathrm{Fe}_{2} \mathrm{O}_{3}$ composite nanofibrous materials. Carbohydr. Poly., 81, 925930. 
34. Benosmane, N. et al. (2010). Preparation, characterization and thermal studies of polymer inclusion cellulose acetate membrane with calix[4] resorcinarenes as carriers. Mater. Sci. Eng. C, 30, 860-867.

35. Amman, D. et al. (1985). Lipophilic salts as membrane additives and their influence on the properties of macro- and micro-electrodes based on neutral carriers. Anal. Chim. Acta, 171, 119-129.

36. Mikhelson, K. et al. (2002). Selectivity of lithium electrodes: Correlation with ion-ionophore complex stability constant and with interfacial exchange current densities. Anal. Chem., 74, 518-527.

37. Shultz, M. M. et al. (2002). Potentiometric estimation of the stability constants of ion-ionophore complexes in ion-selective membranes by the sandwich membrane method: theory, advantages and limitations. Anal. Chem., 74, 510-517.

38. Maurer, G., Lammertz, S. \& Schafer, L. N. (2011). Aqueous solutions of polyelectrolytes: vapor-liquid equilibrium and some related properties. Adv. Poly. Sci., 238, 67-136.

39. Matulis, D. \& Lovrien, R. (1998). 1-Anilino-8-naphthalene sulfonate anionprotein binding depends primarily on ion pair formation. Biophys. J., 74, 422-429.

40. Egorov, V. V., Bolotin, A. A. \& Koronevich, O. S. (2006). Lipophilic ionic additive for controlling the selectivity of ion-selective electrodes reversible to cations of nitrogen-containing organic bases. J. Anal. Chem., 61, 11241129.

41. Telting-Diaz, M. \& Bakker, E. (2001). Effect of lipophilic ion-exchanger leaching on the detection limit of carrier-based ion-selective electrodes. Anal. Chem., 73, 5582-5589.

42. Gabrielli, C. et al. (2004). Investigation of ion-selective electrodes with neutral ionophores and ionic sites by EIS. I. Theory. J. Electroanal. Chem., 570, 275-289.

43. Bakker, E. (2016). Electroanalysis with membrane electrodes and liquidliquid interfaces. Anal. Chem., 88, 395-413.

44. Safari, S., Selvaganapathy, P. R. \& Deen, M. J. (2013). Microfluidic reference electrode with free-diffusion liquid junction. J. Electrochem. Soc., 160, B177-B183.

45. Kisiel, A. et al. (2008). All-solid-state reference electrodes with poly(n-butyl acrylate) based membranes. Electroanal., 20, 318-323.

46. Zhou, J. et al. (2010). Fabrication of a microfluidic ag/agcl reference electrode and its application for portable and disposable electrochemical microchips. Electroph., 31, 3083-3089. 
47. $\mathrm{Hu}, \mathrm{J}$. et al. (2015). All-solid-state reference electrodes based on colloidimprinted mesoporous carbon and their application in disposable paperbased potentiometric sensing devices. Anal. Chem., 87, 2981-2987

48. Heng, L, Y., Alva, S. \& Ahmad, M. (2004). Ammonium ion sensor based on photocured and self-plasticising acrylic films for the analysis of sewage. Sens. Actuat. B Chem., 98, 160-165.

49. Alva, S., Lee, Y. H. \& Ahmad, M. (2006). Screen-printed potassium ion sensor fabricated from photocurable and self-plasticized acrylic film. $J$. Phys. Sci., 12, 139-147.

50. Bendikov, T. A. \& Harmon, T. C. (2005). A sensitive nitrate ion-selective electrode from a pencil lead. J. Chem. Ed., 82, 439-441.

51. IFCC. (2000). Use of ion-selective electrodes for blood-electrolyte analysis. Recommendations for nomenclature, definitions and conventions. Clin. Chem. Lab. Med., 38, 363-370.

52. Polk, B. J. et al. (2006). Ag/agcl microelectrodes with improved stability for microfluidics. Sens. Actuat. B Chem., 114, 239-247.

53. Heng, L. Y., Toth, K. \& Hall, E. A. H. (2004) ion-transport and diffusion coefficients of non-plasticised methacrylic-acrylic ion-selective membranes. Talanta, 63, 73-87. 